University of Nebraska - Lincoln

DigitalCommons@University of Nebraska - Lincoln

Faculty Publications from Nebraska Center for Research on Children, Youth, Families, and Schools
Children, Youth, Families \& Schools, Nebraska Center for Research on

2020

\title{
Culture Moderates the Relationship between Family Obligation Values and the Outcomes of Korean and European American College Students
}

Haein Oh

Toni Falbo

Kejin Lee

Follow this and additional works at: https://digitalcommons.unl.edu/cyfsfacpub

Part of the Bilingual, Multilingual, and Multicultural Education Commons, Child Psychology Commons, Counseling Psychology Commons, Developmental Psychology Commons, Early Childhood Education Commons, Educational Psychology Commons, Family, Life Course, and Society Commons, and the Other Social and Behavioral Sciences Commons

This Article is brought to you for free and open access by the Children, Youth, Families \& Schools, Nebraska Center for Research on at DigitalCommons@University of Nebraska - Lincoln. It has been accepted for inclusion in Faculty Publications from Nebraska Center for Research on Children, Youth, Families, and Schools by an authorized administrator of DigitalCommons@University of Nebraska - Lincoln. 


\title{
Culture Moderates the Relationship between Family Obligation Values and the Outcomes of Korean and European American College Students
}

\author{
Haein $\mathrm{Oh}^{1}$, Toni Falbo ${ }^{1}$ and Kejin Lee ${ }^{1,2}$
}

1 University of Texas at Austin

2 University of Nebraska-Lincoln

Corresponding author - Toni Falbo, Department of Educational Psychology, University of Texas at Austin, 1912 Speedway Ste. 504, Austin, TX 78712, USA; email toni@prc.utexas.edu

\begin{abstract}
Family obligation values have been described as an important element of collectivistic cultures that are related to the development of positive emotional well-being and motivation in high school and college students. The present study tested the hypothesis that culture moderates the relationship between family obligation values and the outcomes of Korean ( $n=249)$ and European American $(n=251)$ college students. The results provided support for this hypothesis. Specifically, for Koreans, family obligation values were significantly and positively correlated with descriptions of parents as being more supportive of the self-determination of their children, which was found to mediate the relationship between family obligation values and student outcomes. Furthermore, family obligation values were more strongly associated with the motivation, self-esteem, and depression of Koreans than European Americans. European American students expressed lower family obligation values and the intensity of these values were unrelated to their emotional well-being. Family obligation values
\end{abstract}

Published in Journal of Cross-Cultural Psychology 51:6 (2020), pp 511-525.

DOI: $10.1177 / 0022022120933682$

Copyright (C) 2020 Haein Oh, Toni Falbo, and Kejin Lee. Published by SAGE Publications. Used by permission. 
were positively correlated with reports of self-determined motivation for Korean students, and negatively correlated with reports of self-determined motivation for European American students. The results are discussed in terms of cultural moderation and self-determination theory.

Keywords: developmental, child/adolescent, family/child rearing, cultural psychology

According to Self-Determination Theory (SDT), children have innate needs for self-determination that must be satisfied to promote optimal development, including the development of healthy levels of emotional well-being and desirable forms of motivation. Furthermore, SDT states if these needs are not satisfied, then lower levels of motivation and wellbeing are to be expected (Ryan \& Deci, 2000).

Self-Determination Theory portrays the family as the foundational context for the satisfaction of these needs and the establishment of developmental histories that support or diminish children's motivation and well-being. Research suggests that when parents satisfy their children's needs for self-determination, their children are likely to achieve autonomous self-regulation at school (Grolnick \& Ryan, 1989) and psychological growth leading to mental health (Ryan \& Deci, 2000). Cultural values and beliefs influence the ways that parents satisfy their children's needs for self-determination, resulting in the acquisition of culturally integrated histories of self-determination that children can apply within multiple contexts, including their educational environments (Ryan \& Deci, 2000).

\section{Korean Parenting}

Self-Determination Theory was developed by psychologists in North America, where the concept of self-determination reflects an ideal of human development (Carver \& Scheier, 1999). Although the creators of SDT present it as reflecting universal needs, processes, and consequences, the applicability of SDT to Koreans has been regarded as uncertain because Korean parents have been characterized as highly involved in the lives of their children (Kwon et al., 2016), much more involved than what is considered normal in the U.S. Korean parenting is based on cultural values and traditions that prioritize connectedness and intimacy within the family, with strong emphasis placed on respect for hierarchy 
and the elderly (Chao, 1994; Chung et al., 2007; Hwang, 1999; Raymo et al., 2015; Ryu, 2007). In addition, Korean culture strongly values family obligations, consisting of respect for family, as well as support for family members, both in the present and the future (Chang, 2013).

At first glance, these intense ties and obligation values within Korean families might be expected to undermine the development of self-determination for Korean college students. However, there is evidence that parental support for children's self-determination is an integral part of traditional Korean values, including family obligation values (FOB). Specifically, Chang (2013) conducted a study exploring the relationship between parental support for self-determination and FOB among Korean college students. She found that Korean college students described their parents as co-planners in their educational goals and as partners who supported them financially and emotionally throughout their college education. Chang labeled this planning-withparents as "coactivity" and found that students who reported greater coactivity with parents also placed more importance on FOB. Furthermore, Chang found that both coactivity and FOB were significantly and positively correlated with the students' life satisfaction, educational satisfaction and educational motivation. These findings led Chang to argue that for Koreans, coactivity reflected parental support of their children's self-determination.

Chang explored these associations further, by testing the possibility that coactivity mediated the relationship between FOB and Korean student outcomes. Her results supported this mediation and Chang interpreted this finding as indicating that coactivity with parents helped Korean college students negotiate their family obligations in ways that promoted their emotional wellbeing and educational motivation. These results suggest that Korean college students interpret their family obligations as consistent with their self-determination. Chang argued that her results supported the basic tenets of SDT.

\section{Family Obligation Values}

Fuligni and his colleagues (Fuligni et al., 1999) introduced the concept of FOB to represent an aspect of collectivistic cultures that reflects the prioritization of family obligations. In order to examine the influence of these values on adolescent development, Fuligni and his colleagues created a generic instrument to measure FOB that would be applicable to a 
wide range of ethnic groups in California. Their initial findings indicated that the Asian Americans in their sample, Chinese and Filipino Americans, had higher FOB than their European American peers.

While Fuligni's original research implied that culture was a moderator of the relationship between FOB and student outcomes, subsequent research has not directly tested culture as a moderator. What we do not know is whether these values have similar relationships to the outcomes of students from collectivistic and individualistic cultures. Based on the literature indicating that FOB are embedded in collectivistic cultures, we expect FOB will have stronger relationships to outcomes for students who grow up in a culture that strongly emphasizes these values, such as those growing up in Korea. In contrast, we expect FOB will have weaker relationships to outcomes for students who grow up in a culture that places less emphasis on FOB, such as those growing up as Americans of European ancestry. In short, the major goal of the present study is to determine if culture moderates the relationships between FOB and student outcomes.

In addition, this study will attempt to replicate conceptually the mediation findings of Chang with another Korean sample, using an instrument created for the purpose of measuring parental support for self-determination. In addition, we test the proposition that parent support for selfdetermination mediates the relationship between FOB and student outcomes for European American students. If parental support for selfdetermination is found to mediate this relationship for students from both cultures, then culture will not be a moderator of this mediation; however, if mediation is found for one culture, but not the other, we will have evidence for the cultural moderation of this mediation.

\section{Statement of Hypotheses}

Hypothesis one. Because Korean culture is more collectivistic, while European American culture is more individualistic, it is expected that Korean students will have higher FOB than European American students.

Hypothesis two. The literature on FOB suggests that these values generally reflect positive parent-child relationships because they are associated with positive student outcomes across a wide 
range of ethnic groups (Fuligni \& Pedersen, 2002). Therefore, it is expected that FOB will be associated with positive student outcomes.

Hypothesis three. The FOB literature implies that culture moderates the relationship between these values and student outcomes. Specifically, the literature suggests that the relationships between FOB and student outcomes are stronger for students from a collectivistic culture, such as Korea, and weaker for students from an individualistic culture, such as the dominant American culture found among European Americans.

Hypothesis four. If the third hypothesis is supported, and culture is found to moderate the relationship between FOB and student outcomes, then it is possible that cultural affiliation will moderate the mediation of parental support for self-determination on the relationship between FOB and student outcomes. It is expected that parental support for self-determination will mediate the relationship between FOB and student outcomes for Koreans, replicating Chang's results. However, if FOB are not strongly correlated with the outcomes of European Americans, as suggested by the third hypothesis, then there may be only weak relationships between FOB and student outcomes. Consequently, the likelihood of finding mediation is low.

\section{Method}

\section{Participants and Procedure}

College students at a public university located in the Southwestern U.S. participated in an online survey for course credit. In order to control for the potential influence of ethnicity, the American sample was limited to students born in the U.S., who also described themselves as White and not Latino $(n=251)$. Korean students $(n=249)$ at a private, midsize university in Seoul, Korea, were asked to participate in this survey as part of in-class activities. They did so by responding to paper questionnaires.

Approval from the IRB of the University of Texas at Austin for this research project (title: Transition to Adulthood, 2012-05-0064) was obtained. 


\section{Instruments}

Family obligation values. Items from the Family Obligation Scale (Fuligni et al., 1999) were used. The original scale consisted of three subscales, Respect for Family, Future Support, and Current Assistance. However, because none of the participants lived with their parents while attending college, the subscale of Current Assistance was not included. Five items measured Respect for Family (e.g., "Follow your parents' advice about choosing a job or major in college") and six items measured Future Support (e.g., "Helping parents financially in the future"). Recent investigators using the FOB have combined the subscales and created a mean generated across all items to represent the intensity of FOB (e.g., Telzer et al., 2015). Participants responded to each item by using a 5-point Likerttype scale, ranging from Not at All to Very Important. None of the items was stated in the reverse direction; higher scores on each item indicated that the participants perceived their parents as expressing stronger FOB.

Need satisfaction scale. Parental support for self-determination was measured using the Need Satisfaction Scale (NSS; La Guardia et al., 2000), which assesses the degree to which respondents feel their needs for selfdetermination (i.e., autonomy, competence, and relatedness) were satisfied by their parents when they were children. The scale consists of nine items on a 7-point Likert-type scale, ranging from Never or Almost Never True to Always or Almost Always True, and participants were asked to answer the same set of items for mothers and fathers separately. Participants were asked how true each of these statements was when they were with their mother (or father). For example, items, such as, "I felt loved and cared about," (reflecting belonging), "I felt like a competent person" (reflecting competence), and "I felt free to be who I am" (reflecting autonomy) followed. Items describing the mother (NSSM) were combined separately from the items describing the father (NSSF), creating two separate scales. For each NSS scale, some of the items were worded in reverse-fashion; these items were reversed scored, with higher scores indicating perceptions of parents as being more supportive of self-determination.

Self-determined motivation in college. The Activity Feeling States Scale (AFS; Reeve \& Sickenius, 1994) was used here to measure the degree of 
self-determined motivation in college. Specifically, scores on the scale reflected the degree to which students perceived their educational environment as satisfying their needs for competency, autonomy, and relatedness. According to Reeve and his colleagues (Reeve, 2012), the more students perceive their educational environments as satisfying these three key psychological needs, the more motivated they are in these environments. Consisting of 10 items that are combined across the three subscales, this instrument measures motivation with a single score. For example, students indicated the degree to which their experiences at their university made them feel that their "skills are improving," (competency), that they "belong" (relatedness), and that they are "free to decide for myself what to do" (autonomy). Participants responded by using a 7-point Likert-type scale, ranging from Strongly Disagree to Strongly Agree, with higher scores indicating greater self-determined motivation.

Rosenberg self-esteem. The Rosenberg Self-Esteem Scale (RSE; Rosenberg, 1965) was used to measure self-esteem, a widely used indicator of well-being (Schmitt \& Allik, 2005). It consists of 10 items, each with a 4-point Likert-type rating scale, ranging from Strongly Agree to Strongly Disagree. The scale scores for each item were coded so that higher scores indicated that the participants had higher self-esteem.

Depression. To measure the frequency with which participants reported symptoms of Depression (CESD), the CESD scale (Radloff, 1977) was used. The scale consists 20 items that ask the participants how often they feel specific symptoms of depression, using a 4-point Likert-type scale, ranging from Rarely to Most of the Time. The scale scores for each item were coded so that higher scores indicated that the participants reported more frequent symptoms of depression.

Translations. We used available Korean translations of the AFS (Institute of Educational Welfare Policy, 2013), RSE (Kim, 2005) and CESD (Bae \& Shin, 2005) instruments. However, there were no available Korean translations of the NSS or Family Obligation Scale (FOB). Therefore, we created our own translations using a three step back-translation procedure. First, the original English version of the NSS and FOB scales was translated into Korean. Then, the Korean versions were translated back into a second English version, and finally, the two English versions were 
compared and, when items were judged to be too discrepant from each other, modifications were made to the Korean translation. The first step was completed by the first author. The second step was completed by two other Koreans who are fluent in both languages. The final step was completed by the first two authors.

Demographic characteristics. Three demographic characteristics were included in our analyses: (a) age (in years), (b) gender ( 1 = male; 2 = female), and (c) a variable representing the mean of the combined mothers' and fathers' educational attainment scores. Five levels of educational attainment were coded for each parent, ranging from 1, completed middle school or less, to 5, possession of a graduate degree. Mothers' and fathers' educational attainment were significantly correlated (Korean, $r=.684$; European Americans, $r=.713$ ).

\section{Results}

Sample characteristics are presented in Table 1. Descriptive statistics about the scale scores (i.e., NSSM, NSSF, FOB, AFS, RSE, CESD) are presented in Table 2. The internal consistency of the scales used in the current study were evaluated within culture by calculating Cronbach's $\alpha$. As shown in Table 2 , the Cronbach's $\alpha$ coefficients indicated that each scale had adequate internal consistency.

\section{Confirmatory Factor Analysis within Culture}

The underlying factor structures of the NSS and FOB scales were examined using a single-factor confirmatory factor analysis within cultural group via Mplus (ver 8; Muthén \& Muthén, 1998- 2017) with the full information maximum likelihood (FIML) estimation to treat missing data. Model fit was evaluated based on the global chi-square $\left(\chi^{2}\right)$ test and approximate fit indices (Asparouhov \& Muthén, 2018). While the global chi-square $\left(\chi^{2}\right)$ statistic and its $p$-values were considered, the approximate fit indices were also used to evaluate the fit since the $\chi^{2}$ known to be sensitive to sample size. Approximate fit indices criteria used in this current analysis were (a) comparative fit index (CFI; $\geq 0.95$ for excellent fit; Hu \& Bentler, 1999), (b) root mean square error of approximation (RMSEA; $\leq 0.08$ for acceptable fit; MacCallum et al., 1996), and (c) root 
Table 1. Description of Samples.
Korea $(n=249)$
U.S. $(n=251)$

Mean age (SD) 21.46 (1.406) 20.30 (1.791)

Gender

\% Male $\quad 24.1 \quad 47.3$

Year in college $(\%)$

$\begin{array}{lll}\text { Freshmen } & 6.8 & 7.7\end{array}$

Sophomore $17.9 \quad 21.2$

Junior $\quad 24.4 \quad 34.1$

Father's Education (\%)

Middle school or less $\quad 6.1$

3.8

High school 15.9

11.1

Some college

$22.3 \quad 18.4$

Bachelors degree $\quad 31.9 \quad 38.6$

Graduate degree $\quad 23.8 \quad 28.1$

Mother's education (\%)

Middle school or less

$7.7 \quad 1.8$

High school 20.9

18.7

Some college 22.4

Bachelors degree $\quad 33.3 \quad 44.6$

Graduate degree $\quad 15.7 \quad 15.6$

The U.S. sample consisted of college students indicating they were born in the U.S., White and not Latino.

Table 2. Descriptive Statistics.

\begin{tabular}{llclc} 
& \multicolumn{3}{l}{ Korea $(n=249)$} & U.S. $(n=251)$ \\
Scale & M $(S D)$ & $\alpha$ & M $(S D)$ & $\alpha$ \\
\hline 1. NSSM & $5.54(0.99)$ & .86 & $5.54(1.12)$ & .89 \\
2. NSSF & $5.30(0.94)$ & .85 & $5.32(1.26)$ & .91 \\
3. FOB & $3.84(0.48)$ & .91 & $3.15(0.69)$ & .92 \\
4. AFS & $4.81(0.92)$ & .89 & $5.54(0.85)$ & .91 \\
5. RSE & $2.45(0.18)$ & .87 & $3.10(0.57)$ & .87 \\
6.CESD & $1.92(0.52)$ & .80 & $1.66(0.49)$ & .85 \\
\hline
\end{tabular}

NSSM = need satisfaction scale for mothers; NSSF = need satisfaction scale for fathers; FOB = family obligation values; AFS = motivation; RSE = Rosenberg self-esteem; CESD = depression. U.S. students were born in the U.S., White and not Latino.

$* \mathrm{p}<.05 ; * * \mathrm{p}<.01 ; * * * \mathrm{p}<.001$

mean square residual (SRMR) ( $\leq 0.08$ for acceptable fit; Asparouhov \& Muthén, 2018; Hu \& Bentler, 1999). The results are presented in Table 3 and indicate that the fit for both NSS scales and the FOB scale was adequate and supported our proceeding with invariance tests. 
Table 3. Results of One-Factor CFAs for Family Obligation and Need Satisfaction scales for Korean and American Samples.

\begin{tabular}{llllll} 
Group & $\mathrm{X}^{2}(d f)$ & CFI & RMSEA & $90 \%$ RMSEA CI & SRMR \\
\hline NSSM & & & & & \\
Korea & $44.283^{*}(15)$ & 0.963 & 0.089 & $(0.059,0.119)$ & 0.039 \\
U.S. & $29.595^{*}(15)$ & 0.990 & 0.062 & $(0.028,0.095)$ & 0.020 \\
NSSF & & & & & \\
Korea & $35.755^{*}(15)$ & 0.974 & 0.075 & $(0.043,0.106)$ & 0.032 \\
U.S. & $36.781^{*}(15)$ & 0.983 & 0.076 & $(0.045,0.108)$ & 0.027 \\
FOB & & & & & \\
Korea & $73.579^{*}(29)$ & 0.964 & 0.072 & $(0.052,0.092)$ & 0.057 \\
U.S. & $39.001^{*}(29)$ & 0.976 & 0.037 & $(0.000,0.065)$ & 0.038 \\
\hline
\end{tabular}

NSSM = need satisfaction scale for mothers; NSSF = need satisfaction scale for fathers; FOB = family obligation values.

U.S. sample consists of US-born citizens who were White, but not Latino.

$* p<.05$

\section{Measurement Invariance Testing}

The measurement invariance test was conducted for the FOB and NSS scales in order to assess whether these scales are comparable between the Korean and American cultures (Xu \& Barnes, 2011). Sequential measurement invariance tests of nested models were conducted and measurement invariance was considered met if the difference in CFI values $(\triangle \mathrm{CFI})$ was 0.01 or less (Chen, 2007; Cheung \& Rensvold, 2002; Xu \& Barnes, 2011).

The results for both the NSS scores are presented in Tables 4 and 5 . The measurement invariance test started from the configural invariance step where the NSS items exhibited a similar pattern of factor loadings between the two cultures. Subsequently, metric invariance was tested by constraining the factor loadings to be equal between the two samples and the results supported metric invariance on both scales (see Tables 4 and 5). In order to determine if a higher level of invariance could be found, tests for scalar invariance were conducted. As shown in Tables 4 and 5 , the criteria establishing partial, but not full scalar invariance was met for both NSSM and NSSF scores. These results indicate that the NSS scales are comparable between the two cultures and this allowed for statistical comparisons on factor means of the two NSS scales between the two cultures (Byrne et al., 1989; Xu \& Barnes, 2011). 
Table 4. Results of Stepwise Invariance Test for NSSM.

\begin{tabular}{lrrrrr} 
Model & $\mathrm{X}^{2}(d f)$ & CFI & RMSEA [90\% CI $]$ & SRMR & $\Delta$ CFI \\
\hline Configural & $73.877^{*}(30)$ & 0.980 & $0.076[0.055,0.099]$ & 0.031 & \\
Metric & $102.219^{*}(36)$ & 0.970 & $0.086[0.066,0.106]$ & 0.082 & 0.010 \\
Scalar & $195.261^{*}(44)$ & 0.931 & $0.117[0.101,0.134]$ & 0.100 & 0.039 \\
Partial scalar & $166.036^{*}(43)$ & 0.944 & $0.107[0.090,0.124]$ & 0.088 & 0.026 \\
Partial scalar 2 & $137.912^{*}(42)$ & 0.956 & $0.096[0.078,0.114]$ & 0.084 & 0.014 \\
Partial scalar 3 & $117.787^{*}(41)$ & 0.965 & $0.087[0.068,0.105]$ & 0.081 & 0.005 \\
\hline
\end{tabular}

Invariance through, and including, partial scalar invariance was found for NSSM. Three partial scalar models were tested, and the third model produced acceptable levels of fit indices.

$* p<.05$

Table 5. Results of Stepwise Invariance Test for NSSF.

\begin{tabular}{lrrrrr} 
Model & $\mathrm{X}^{2}(d f)$ & CFI & RMSEA $[90 \% \mathrm{CI}]$ & SRMR & $\Delta$ CFI \\
\hline Configural & 72.536*(30) & 0.980 & $0.075[0.053,0.098]$ & 0.029 & \\
Metric & $99.469^{*}(36)$ & 0.970 & $0.084[0.065,0.104]$ & 0.076 & 0.010 \\
Scalar & $199.428^{*}(44)$ & 0.927 & $0.119[0.102,0.136]$ & 0.122 & 0.043 \\
Partial scalar & $172.059^{*}(43)$ & 0.939 & $0.110[0.093,0.127]$ & 0.112 & 0.031 \\
Partial scalar 2 & $125.917^{*}(42)$ & 0.960 & $0.089[0.072,0.108]$ & 0.097 & 0.010 \\
\hline
\end{tabular}

Invariance through, and including, partial scalar invariance was found for NSSF. Two partial scalar models were tested and the second model produced acceptable levels of fit indices.

$* p<.05$

Table 6. Results of Stepwise Invariance Test for FOB Scale.

\begin{tabular}{lrrrrr} 
Model & $X^{2}(d f)$ & CFI & RMSEA [90\% CI $]$ & SRMR & $\Delta$ CFI \\
\hline Configural & $112.580^{*}(58)$ & 0.97 & $0.059[0.042,0.075]$ & 0.049 & \\
Metric & $154.496^{*}(67)$ & 0.947 & $0.069[0.055,0.083]$ & 0.077 & 0.020 \\
Partial Metric & $137.059^{*}(66)$ & 0.97 & $0.063[0.048,0.078]$ & 0.069 & 0.010 \\
Scalar & $1014.212^{*}(77)$ & 0.428 & $0.211[0.199,0.223]$ & 0.277 & 0.529 \\
Partial Scalar 1 & $945.045^{*}(76)$ & 0.470 & $0.204[0.193,0.216]$ & 0.269 & 0.487 \\
Partial Scalar 2 & $844.383^{*}(75)$ & 0.531 & $0.194[0.182,0.206]$ & 0.269 & 0.426 \\
\hline
\end{tabular}

Invariance through, and including, partial metric invariance was found for FOB. Two partial scalar models were tested, but neither produced acceptable levels of fit indices.

$* p<.05$

Similar testing was conducted on a scale that combined the NSSM items with the NSSF items to create a joint parental support for self-determination scale. However, the results of these tests of measurement invariance did not support strong equivalence between the Korean and English language versions. Therefore, the analyses used the two scales separately when testing hypotheses. 
The measurement invariance results for the FOB are presented in Table 6. These results support configural and partial metric invariance, consequently, tests for scalar invariance were conducted. However, as shown in Table 6, the scalar invariance was not met for FOB as the approximate model fit indices of the full scalar model was very poor, in terms of the CFI, RMSEA, and SRMR. Although tests for partial scalar invariance were conducted by releasing individual item's intercepts, based on modification indices, partial scalar invariance was also never met. Overall, this pattern of findings means that while statistical comparison of factor means between the Korean and American versions (Byrne et al., 1989; Xu \& Barnes, 2011) was not appropriate, hence statistical comparison of raw FOB scores between cultures was used. Based on the results from the measurement invariance test for the NSSM, NSSF, and FOB scales, data analyses corresponding to the four hypotheses using raw scores, instead of factor scores, were conducted.

\section{Demographic Variables}

Table 7 presents findings about demographic differences between the two samples. The correlation between the dummy variable representing culture and the demographic variables indicated that the students in the Korean sample were significantly older and more likely to be female than their European American counterparts. Furthermore, the results in Table 7 indicate that there were significant correlations between demographic variables and the scores representing FOB and student outcome variables. Consequently, these variables were covaried in all analyses testing hypotheses, reported below.

\section{Hypothesis Testing}

Hypothesis one. The first hypothesis stated that the FOB scores of Korean students would be significantly higher than the FOB scores of American students of European ancestry. To test this hypothesis, the two samples were combined and a correlation between a dummy variable representing culture and FOB scores was conducted. The problem with measurement invariance notwithstanding, this bivariate correlation revealed a significant difference, which provided support for the first hypothesis and are presented in Table 7. 
Table 7. Correlations Among Major Variables for Korean and U.S. Samples Combined $(n=500)$.

\begin{tabular}{|c|c|c|c|c|c|c|c|c|c|c|}
\hline Variables & Age & Gender & ParentEd & Culture & FOB & NSSM & NSSF & AFS & RSE & CESD \\
\hline Age & - & & & & & & & & & \\
\hline Gender & -0.007 & - & & & & & & & & \\
\hline Parent Ed & 0.009 & 0.026 & - & & & & & & & \\
\hline Culture & $-0.366^{* *}$ & $-0.259^{* *}$ & 0.049 & - & & & & & & \\
\hline FOB & $0.222^{* *}$ & $0.133^{* *}$ & $0.081^{*}$ & $-0.446^{* *}$ & - & & & & & \\
\hline NSSM & -0.002 & -0.027 & 0.028 & -0.009 & $0.185^{* * *}$ & - & & & & \\
\hline NSSF & 0.010 & 0.013 & 0.011 & 0.056 & $0.177^{* * *}$ & $0.330^{* * *}$ & - & & & \\
\hline AFS & $-0.093^{* *}$ & $-0.101^{*}$ & $0.121^{*}$ & $0.321^{* * *}$ & 0.005 & $0.340^{* * *}$ & $0.187^{* *}$ & - & & \\
\hline RSE & $-0.168^{* * *}$ & -0.051 & -0.042 & $0.415^{* * *}$ & $0.245^{* * *}$ & $0.156^{* *}$ & $0.152^{* *}$ & $0.220^{* *}$ & - & \\
\hline CESD & $0.132^{* * *}$ & $0.167^{* *}$ & -0.009 & $-0.201^{* * *}$ & $-0.132^{* *}$ & $-0.377^{* *}$ & $-0.161^{* *}$ & $-0.531^{* * *}$ & $-0.294^{* * *}$ & - \\
\hline
\end{tabular}

Gender ( 1 = Male, 2 = Female), Culture ( 1 = Korean, 2 = European American). FOB = family obligation; NSSM = need satisfaction scale for mothers; NSSF = need satisfaction scale for fathers AFS = motivation; RSE $=$ Rosenberg self esteem; CESD = depression.

${ }^{*} p<.05 ;{ }^{* *} p<.01 ;{ }^{* * *} \underline{p}<.001$

There were additional differences found between the two samples. The findings of higher RSE scores for European Americans than Koreans (e.g., Jung \& Lee, 2006) and higher CESD scores for Koreans than European Americans (Stankov, 2013; Young et al., 2010), are consistent with the findings of previous research. Interestingly, Table 7 presents a few novel findings about cultural differences. Specifically, Korean students were found to have lower AFS scores than European American students. More remarkably, Korean students and European American students were found to be similar in their evaluation of their parents as supporting their self-determination.

Hypothesis two. The second hypothesis stated that FOB would be significantly correlated with student outcomes. The results are presented in Table 7 and partially support this hypothesis. Specifically, the correlations indicate that students with higher FOB scores had significantly higher RSE and lower CESD scores. However, in terms of motivation, the non-significant correlation between FOB and AFS indicated that this part of the second hypothesis was not supported. Previous research about FOB and indicators of aspects of academic motivation has reported positive correlations between FOB and some, but not all indicators of academic motivation (Fuligni et al., 1999; Fuligni \& Pedersen, 2002). No previous research has considered self-determined motivation in college as an indicator of academic motivation. 
Other results presented in Table 7 are consistent with expectations based on SDT. Specifically, the results indicated that students who perceived their parents as more supportive of their selfdetermination reported higher levels of self-determined motivation in college, higher selfesteem, and lower depression.

The results presented in Table 7 indicate that FOB scores were positively and significantly correlated with NSSM and NSSF. This finding suggests that FOB are generally consistent with parental support for selfdetermination. Similarly, the results in Table 7 indicate that FOB scores are associated with better well-being among college students.

Hypothesis three. To test for the moderating effect of cultural affiliation on the relationship between FOB and student outcomes, we conducted a PROCESS analysis, developed by Preacher and Hayes (2008), using SPSS.

As shown in Table 8, the findings showed that culture significantly moderated the association between FOB and AFS, $R^{2}$ change $=.019$, the association between FOB and RSE, $R^{2}$ change $=.009$, and the association between FOB and CESD, $R^{2}$ change $=.013$.

Table 8. Regression Model Summary of FOB and Culture.

\begin{tabular}{|c|c|c|c|c|c|c|c|c|c|}
\hline \multirow[b]{2}{*}{ Variables } & \multicolumn{3}{|c|}{ AFS } & \multicolumn{3}{|c|}{ RSE } & \multicolumn{2}{|c|}{ CESD } & \multirow[b]{2}{*}{$t$} \\
\hline & $B$ & $S E$ & $t$ & $B$ & $S E$ & $t$ & $B$ & $S E$ & \\
\hline Gender & 0.003 & 0.081 & 0.040 & 0.077 & 0.044 & 1.768 & 0.107 & 0.045 & $2.361^{*}$ \\
\hline Age & -0.027 & 0.019 & -0.607 & 0.031 & 0.012 & 0.714 & .047 & 0.009 & 0.874 \\
\hline Culture & 0.003 & 0.000 & $9.086^{* * *}$ & 0.002 & 0.000 & $10.861^{* * *}$ & -0.209 & 0.031 & $-5.476^{* * *}$ \\
\hline $\begin{array}{l}\text { Family Obligation } \times \\
\text { Culture }\end{array}$ & 0.342 & 0.121 & $3.028^{* * *}$ & 0.089 & 0.060 & $1.468^{* *}$ & 0.182 & 0.073 & $2.668^{* * *}$ \\
\hline Parents' Education & 0.026 & 0.040 & $0.908^{*}$ & 0.041 & 0.037 & 0.705 & -0.057 & 0.036 & -1.202 \\
\hline $\begin{array}{l}\text { Need Satisfaction } \\
\text { Scale for Mothers }\end{array}$ & 0.291 & 0.036 & $8.022^{* * *}$ & 0.097 & 0.020 & $4.971^{* * *}$ & -0.177 & 0.021 & $-8.519^{* * *}$ \\
\hline $\begin{array}{l}\text { Need Satisfaction } \\
\text { Scale for Fathers }\end{array}$ & 0.039 & 0.034 & $1.148^{*}$ & -0.057 & 0.018 & $-3.101^{* *}$ & -0.112 & 0.019 & $-5.032^{* * *}$ \\
\hline \multicolumn{10}{|c|}{ Simple slopes of family obligation and culture } \\
\hline Korean & 0.347 & 0.115 & $3.022^{* *}$ & 0.158 & 0.060 & $1.466^{* * *}$ & -0.277 & 0.066 & $-2.673^{* *}$ \\
\hline American & -0.190 & \multicolumn{2}{|c|}{$0.0782 .446^{*}$} & -0.038 & 0.040 & -0.968 & 0.037 & 0.045 & 0.798 \\
\hline
\end{tabular}

$\mathrm{N}=500$ Gender (1= Male, 2 = Female), Culture (1= Korean, 2 = European American). FOB = family obligation; NSSM = need satisfaction scale for mothers; NSSF = need satisfaction scale for fathers AFS = Motivation; RSE = Rosenberg selfesteem; CESD = depression. ${ }^{*} p<.05 ;{ }^{* *} p<.01 ;{ }^{* * *} p<.001$ 


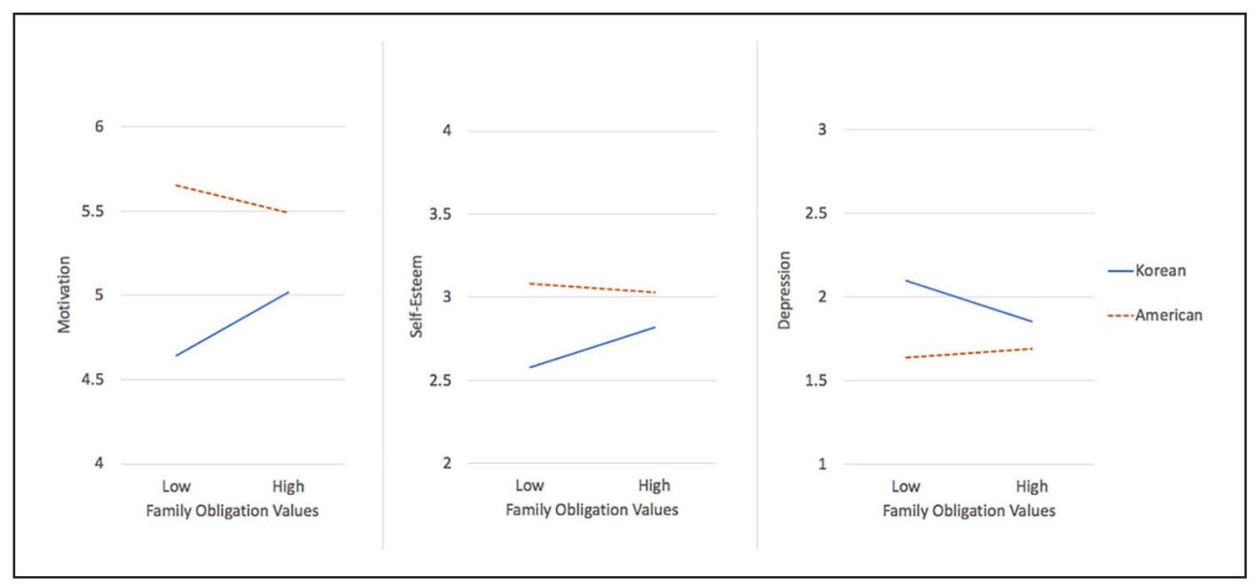

Figure 1. Interaction between family obligation values and cultural affiliation in predicting motivation, self-esteem, and depression.

Table 8 also presents information comparing the simple slopes of the FOB and outcome relationships by culture. These slopes are illustrated in three panels of Figure 1. As shown in the first panel, the results indicated that the association between FOB and motivation (AFS) was stronger for Koreans than European Americans. Similarly, the second panel of Figure 1 shows that the association between FOB and self-esteem (RSE) was stronger for Koreans than for European Americans. Lastly, the third panel of Figure 1 shows that the association between FOB and depression (CESD) was stronger for Koreans than European Americans.

Hypothesis four. To test whether culture moderated the mediation of NSSM and NSSF on the relationship between FOB and the student outcomes, data analyses were conducted using the PROCESS procedure for SPSS Release 2.15 (Hayes, 2018a, 2018b). NSSM and NSSF were considered separately as mediators because the results of the invariance testing indicated that high levels of invariance were found between the Korean and English language versions only when these two scales were considered separately.

The results are presented in Table 9 and indicate that culture did moderate the mediation. For both NSSM and NSSF, indices of moderated mediation were found to be statistically significant.

Furthermore, the conditional indirect effects were found to be statistically significant for Koreans, but not European Americans. These results 


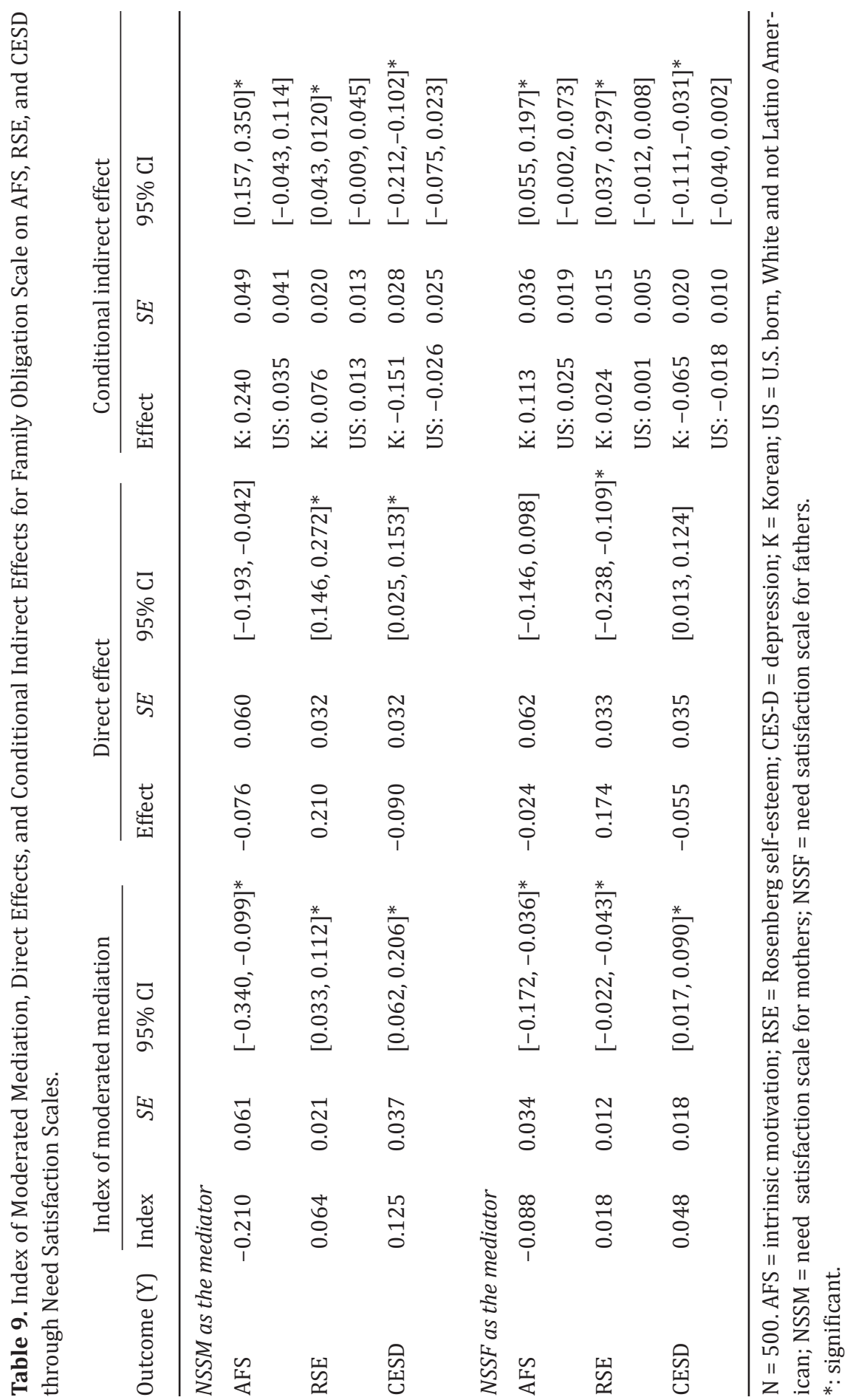


indicate that parental support for self-determination mediated the relations between FOB and student outcomes for Korean, but not European American students. For Koreans, FOB are consistent with parental support for self-determination. For European Americans, family obligations are independent of parental support for self-determination.

\section{Discussion}

Within developmental psychology, FOB have been portrayed as embedded within collectivistic cultures (Chang, 2013; Fuligni et al., 1999). The research literature surrounding FOB has found that these values correlate positively with the outcomes of college students from collectivistic cultures, in this case, Korea, and are mediated by parental support for self-determination (Chang, 2013). What has remained uncertain was whether FOB would correlate positively with the outcomes of college students from more individualistic cultures, such the dominant culture of Americans of European ancestry. The present results suggest that FOB generally are unrelated to the well-being of European American college students and are negatively associated with their self-determination motivation in college.

This study integrated the cultural concept of FOB with the principles of Self Determination Theory. The present results replicated previous findings about Korean college students and extended what is known about FOB within individualistic cultures. The present study succeeded in demonstrating that college students from a more individualistic culture view FOB as less important than college students from a more collectivistic culture. Furthermore, this study succeeded in demonstrating that this cultural difference moderates the relationship between FOB and student outcomes. That is, the results indicated that FOB were associated with positive wellbeing for Korean students, but for European American students, these values had no significant association with their well-being.

In terms of motivation in college, the results of this study indicate that FOB were negatively correlated with experiencing self-determined motivation in college for European Americans. In contrast, for Koreans, these results indicate that FOB were positively correlated with experiencing self-determined motivation in college. These completely opposite relationships suggest that FOB influence college motivation very differently 
for members of individualistic cultures, compared to members of collectivistic cultures. Overall, these findings suggest that FOB appear to benefit college students from more collectivistic cultures. However, for those from individualistic cultures, the results suggest that FOB are not relevant to the emotional well-being of European American college students and may even discourage their experience of self-determined motivation in college.

Consistent with the principles of Self Determination Theory, the results indicated that for both Korean and European American students, the more students described their parents as supporting their self-determination, the better the students' mental health and the higher their self-determined motivation in college. It is interesting to note that there were no significant differences found between Korean and European American students in the degree to which they described their parents as supporting their self-determination. This finding is even more remarkable because the tests of measurement invariance for these scales indicated a high level of measurement invariance between the Korean and English language versions of the scales measuring parental support for self-determination.

Given the finding of cultural moderation of the relationship between FOB and student outcomes, it was not surprising that evidence of moderated mediation was also found. That is, we found that parental support for self-determination mediated the relationship between FOB and student outcomes for Korean students, but not European American students. Overall, these findings suggest that parental support for self-determination was consistent with FOB among the Korean sample. For them, parental support for self-determination was significantly correlated with the degree of FOB. However, for European American students, no significant relationship between FOB and parental support for selfdetermination was found.

One of the limitations of this study is the lower level of measurement invariance obtained for the Korean and English language measures of FOB. The results of the tests of measurement invariance suggested that only lower levels of invariance were achievable with these data. This finding indicates that even though the Korean instrument measuring FOB had been carefully translated from the English version, the meanings of the items were not precisely the same. Nonetheless, the level achieved allowed us to apply statistical comparisons between raw 
scores. The fact that the samples of this study consisted entirely of college students is another limitation. Although we controlled statistically for the effects of background factors such as age, gender, and parent's education, it is possible that our findings would be different if we included youth who were not college students, or were members of subcultures with distinctly different cultural beliefs surrounding family obligations. Indeed, there are many American youth who grow up in collectivistic home cultures, and the findings we reported for European Americans may not represent them.

Declaration The authors declared no potential conflicts of interest with respect to the research, authorship, and publication of this article.

Funding This research was supported by Grant, P2CHD042849, Population Research Center, awarded to the Population Research Center at The University of Texas at Austin by the Eunice Kennedy Shriver National Institute of Child Health and Human Development. The content is solely the responsibility of the authors and does not necessarily represent the official views of the National Institutes of Health.

\section{References}

Asparouhov, T., \& Muthén, B. (2018, May 2). SRMR in Mplus. Technical Report. http:// www.statmodel.com/recentpapers.shtml .

Bae, S. W., \& Shin, W. S. (2005). The factor structure of CES-D scale (The Center for Epidemiologic Studies Depression Scale): An application of confirmatory factor analysis. Health and Social Science, 18(18), 165-190.

Byrne, B. M., Shavelson, R. J., \& Muthén, B. (1989). Testing for the equivalence of factor covariance and mean structures: The issue of partial measurement invariance. Psychological Bulletin, 105(3), 456-466.

Carver, C. S., \& Scheier, M. F. (1999). Themes and issues in the self-regulation of behavior. In R. S. Wyer, Jr. (Ed.), Perspectives on behavioral self-regulation: Advances in social cognition (Vol. 12, pp. 1-105). Lawrence Erlbaum Associates, Inc.

Chao, R. K. (1994). Beyond parental control and authoritarian parenting style: Understanding Chinese parenting through the cultural notion of training. Child Development, 65(4), 1111-1119.

Chang, E. S. (2013). Negotiating family obligations and educational goals among college-enrolled youth on Jeju Island, Korea. Journal of Research on Adolescence, 23(1), 25-34. doi:10.1111/j.1532- 7795.2012.00814.x

Chen, F. F. (2007). Sensitivity of goodness of fit indexes to lack of measurement invariance. Structural Equation Modeling, 14(3), 464-504. 
Cheung, G. W., \& Rensvold, R. B. (2002). Evaluating goodness-of-fit indexes for testing measurement invariance. Structural Equation Modeling, 9(2), 233-255.

Chung, O., Chung, S., Kim, K., \& Park, Y. (2007). A study on the differences of family values and parental role responsibility among three generations. Journal of Family Relations, 12(2), 215-249.

Fuligni, A. J., \& Pedersen, S. (2002). Family obligation and the transition to young adulthood. Developmental Psychology, 38(5), 856-868.

Fuligni, A. J., Tseng, V., \& Lam, M. (1999). Attitudes toward family obligations among American adolescents from Asian, Latin American, and European backgrounds. Child Development, 70(4), 1030-1044.

Grolnick, W, S., \& Ryan, R. M. (1989). Parent styles associated with children's selfregulation and competence in school. Journal of Educational Psychology, 81(2), 143-154.

Hayes, A. F. (2018a). Introduction to mediation, moderation, and conditional process analysis: A regression-based perspective (2nd ed.). The Guilford Press.

Hayes, A. F. (2018b). Partial, conditional, and moderated moderated mediation: Quantification, inference, and interpretation. Communication Monographs, 85(1), 4-40.

Hu, L. T., \& Bentler, P. M. (1999). Cutoff criteria for fit indexes in covariance structure analysis: Conventional criteria versus new alternatives. Structural Equation Modeling, 6(1), 1-55.

Hwang, K. (1999). Filial piety and loyalty: Two types of social identification in Confucianism. Asian Journal of Social Psychology, 2(1), 163-183. doi:10.1111/1467-839X.00031

Institute of Educational Welfare Policy. (2013). Development of index and diagnostic measures related to educational welfares of middle-school students.

Jung, J., \& Lee, S. H. (2006) Cross-cultural comparisons of appearance self-schema, body image, selfesteem, and dieting behavior between Korean and U.S. women. Family and Consumer Sciences Research Journal, 34(4), 350-365.

Kim, Y. H. (2005). The relationship between open communication of the parents and children's behavior problem: Self-esteem and self-control as a mediating variable (Master's thesis). Sookmyung Women's University.

Kwon, K.-A., Yoo, G., \& Bingham, G. E. (2016). Helicopter parenting in emerging adulthood: Support or barrier for Korean college students' psychological adjustment? Journal of Child and Family Studies, 25(1), 136-145. doi:10.1007/ s10826-015-0195-6

La Guardia, J. G., Ryan, R. M., Couchman, C. E., \& Deci, E. L. (2000). Within-person variation in security of attachment: A self-determination theory perspective on attachment, need fulfillment, and well-being. Journal of Personality and Social Psychology, 79(3), 367-384.

MacCallum, R. C., Browne, M. W., \& Sugawara, H. M. (1996). Power analysis and determination of sample size for covariance structure modeling. Psychological Methods, 1(2), 130-149. 
Muthén, L. K., \& Muthén, B. O. (1998-2017). Mplus User's Guide. (8th ed.). Muthén \& Muthén

Preacher, K. J., \& Hayes, A. F. (2008). Asymptotic and resampling strategies for assessing and comparing indirect effects in multiple mediator models. Behavior Research Methods, 40(3), 879-891. doi:10.3758/BRM.40.3.879.

Radloff, L. S. (1977). The CES-D Scale: A self-report depression scale for research in the general population. Applied Psychological Measurement, 1(3), 385-401. doi:10.1177/014662167700100306

Raymo, J. M., Park, H., Xie, Y., \& Yeung, W. J. (2015). Marriage and family in East Asia: Continuity and change. Annual Review of Sociology, 41(1), 471-492. doi:10.1146/ annurev-soc-073014-112428

Reeve, J. (2012). Activity-Feeling States (AFS) Scale. Retrieved April 27, 2012, from http://www.johnmarshallreeve.org/questionnaires.html

Reeve, J., \& Sickenius, B. (1994). Development and validation of a brief measure of the three psychological needs underlying intrinsic motivation: The AFS scales. Educational and Psychological Measurement, 54(2), 506-515.

Rosenberg, M. (1965). Society and the adolescent self-image. Princeton University Press.

Ryan, R. M., \& Deci, E. L. (2000). Self-Determination theory and the facilitation of intrinsic motivation, social development, and well-being. American Psychologist, 55(1), 68-78. doi:10.1037//0003-066X.55.1.68

Ryu, J. (2007). A study on the parent-child relation, familism, and Hyo. Korean Journal of Parent Education, 4(2), 81-94.

Schmitt, D. P., \& Allik, J. (2005). Simultaneous administration of the Rosenberg selfesteem scale in 53 nations: Exploring the universal and culture-specific features of global self-esteem. Journal of Personality and Social Psychology, 89(4), 623-642.

Stankov, L. (2013). Depression and life satisfaction among European and Confucian adolescents. Psychological Assessment, 25(4), 1220-1234. doi:10.1037/a0033794

Telzer, E. H., Tsai, K. M., Gonzales, N., \& Fuligni, A. J. (2015). Mexican American adolescents' family obligation values and behaviors: Links to internalizing symptoms across time and context. Developmental Psychology, 51(1), 75-86.

Xu, L., \& Barnes, L. L. B. (2011). Measurement invariance of scores from the Inventory of School Motivation across Chinese and U.S. college students. International Journal of Testing, 11(2), 178-210.

Young, C. B., Fang, D. Z., \& Zisook, S. (2010). Depression in Asian-American and Caucasian undergraduate students. Journal of Affective Disorders, 125(1-3), 379382. doi:10.1016/j.jad.2010.02.124 